\title{
A Case of Primary Leiomyosarcoma of the Heart
}

\author{
Shigetaka Takamizawa, Ken-ichi Sugimoto, Hiroshi Tanaka, \\ Osamu SAKaI, Toyohiko AraI* and Atsushi SaItoH**
}

\begin{abstract}
A 53-year-old male was hospitalized with complaints of cough, fever and backache. Twodimensional echo-cardiography showed a pericardial echo-free space and a mass in the right atrium. Based on the MRI findings showing a pericardial mass originating from the atrial tumor, the final diagnosis of Ieiomyosarcoma was made by a percutaneous pericardial biopsy. Despite various therapies, the patient died after $3 \mathrm{wk}$. Because of its rareness (to date only 25 case reports), a premortem diagnosis of primary cardiac leiomyosarcoma is generally difficult. However, we feel that MRI and a subsequent biopsy is quite useful for making an early diagnosis of this disease.
\end{abstract}

(Internal Medicine 31: 265-268, 1992)

Key words: MRI, percutaneous cardiac biopsy

\section{Introduction}

Cardiac tumor is a very rare disease. In particular, primary malignant tumor of the heart is extremely rare, and thus establishment of the diagnosis while the patient is alive is difficult. For morphological diagnosis of the tumor, two-dimensional echocardiography (2DE) has been used as the first step, followed by CT scanning (including enhanced CT and dynamic CT) and cardioangiography. Although these examinations can provide some information on the morphology of intracardiac lesions, it is very difficult to determine their properties (e.g., differentiation from thrombus and pericardial lesions). We describe here a case with primary leiomyosarcoma of the heart; for the diagnosis magnetic resonance imaging (MRI) was quite useful from a radiological point of view, and percutaneous biopsy of the tumor was possible.

\section{Case Report}

A 53-year-old male company employee had the chief complaints of backache, cough and fever. His past history and family history were not contributory. The patient began to suffer from backache and arthralgia of the left shoulder from mid-December 1988. He visited a neighborhood clinic in mid-January 1989 with the com- plaint of cough and a fever of $37^{\circ} \mathrm{C}$ in addition to the above symptoms. Pleural effusion was noted on the left side of the chest X-ray film, thus the patient was admitted to our department on January 23, 1989. The medical check-up he had undergone 2 months before admission only disclosed slight enlargement of the cardiac shadow on the indirect chest X-ray film.

On admission, the patient had a body temperature of $38^{\circ} \mathrm{C}$, pulse rate of $120 / \mathrm{min}$ and normal blood pressure. The palpebral conjunctiva was not anemic. Although weakened respiratory sounds were noted in the left thoracic region, no rale or heart murmur was heard. There was no hepato-splenomegaly or edema in the lower extremities. No cervical or axillary lymph nodes were palpable.

Laboratory examination on admission revealed anemia, markedly increased LDH, increased ESR, positive CRP, slightly decreased coagulability and an increase only in CA 125 as a tumor marker. Arterial blood gas analysis showed a decrease in oxygen concentration. The pleural effusion was bloody and exudative, negative for culture tests; cytological examination disclosed class II. Electrocardiography showed negative $\mathrm{T}$ waves in $\mathrm{V}_{4-6}$ but was without low voltage in any lead. Chest $\mathrm{X}$-ray examination revealed voluminous pleural effusion on the left side and irregular margin of the right second arch of the cardiac shadow (Fig. 1).

From The Second Department of Internal Medicine and *The First Department of Internal Medicine, Jikei University School of Medicine, Tokyo, **:The Department of Internal Medicine, Jikei University School of Medicine, Kashiwa Hospital, Kashiwa

Received for publication March 11, 1991; Accepted for publication July 10, 1991

Reprint requests should be addressed to Shigetaka Takamizawa, MD, The Second Department of Internal Medicine, Jikei University School of Medicine, 3-25-8 Nishi-shinbashi, Minato-ku, Tokyo 105, Japan 


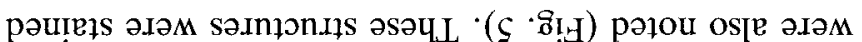

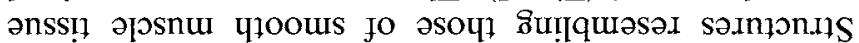

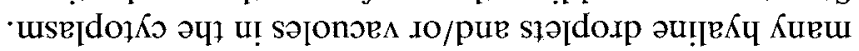

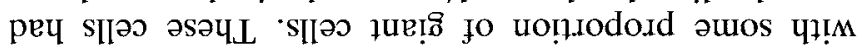

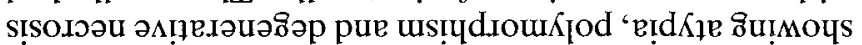

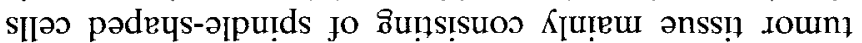

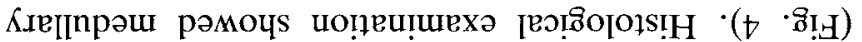

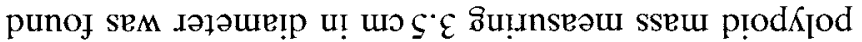

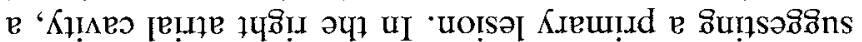

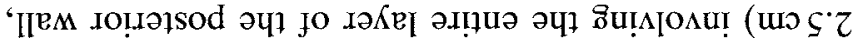

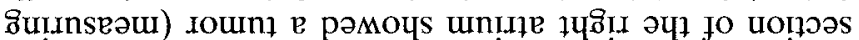

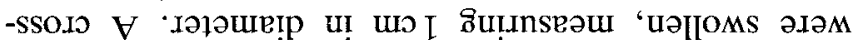

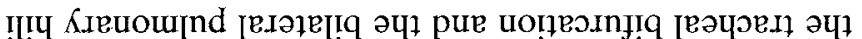

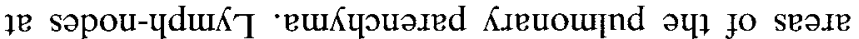

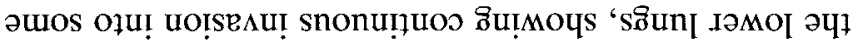

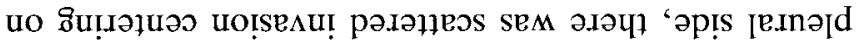

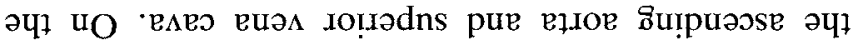

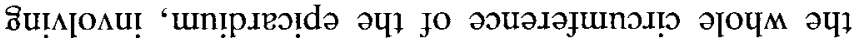
рәрелu! peч Joum

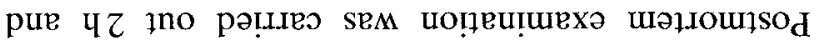

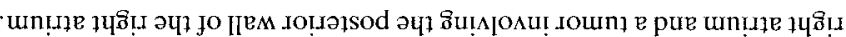

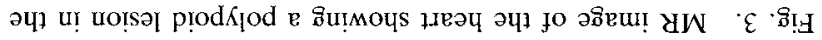

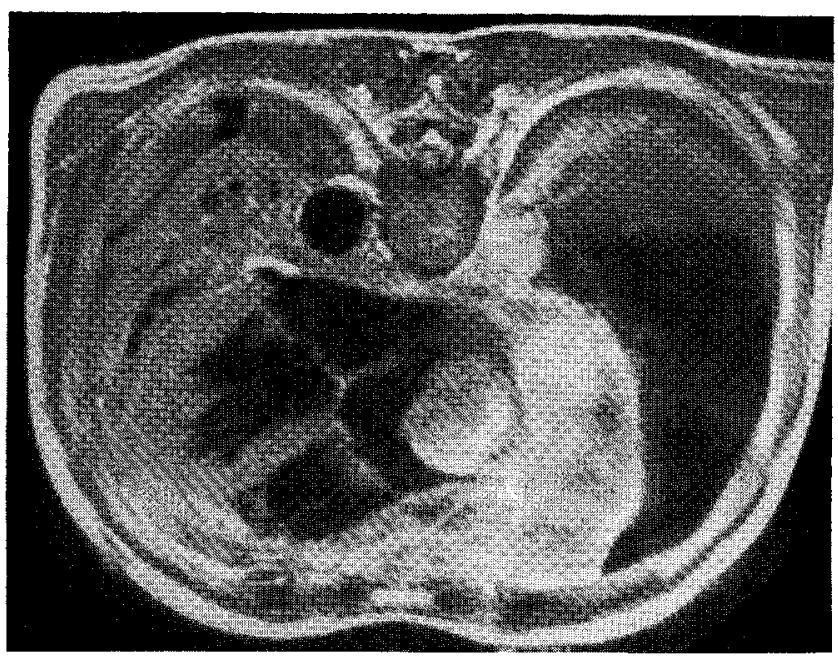

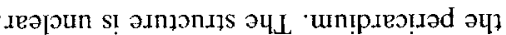

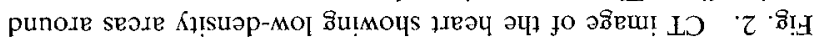

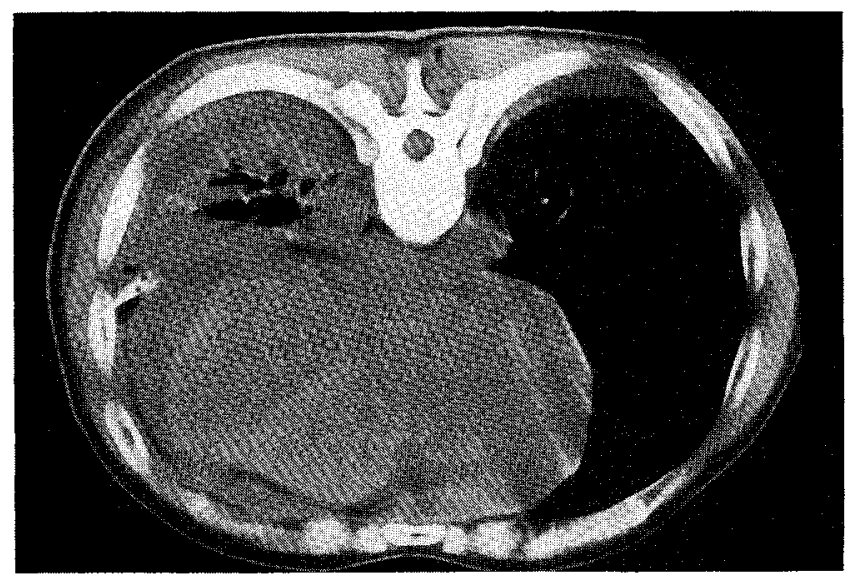

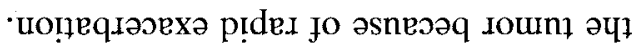

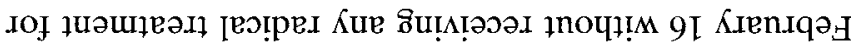

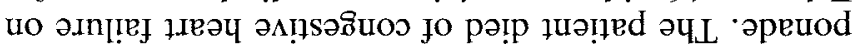

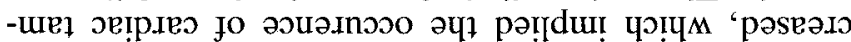

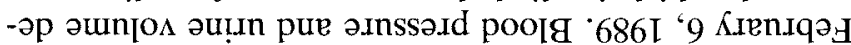

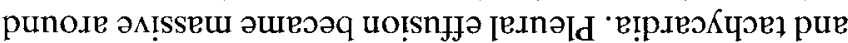

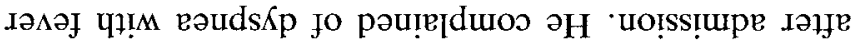

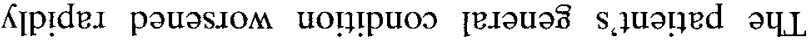

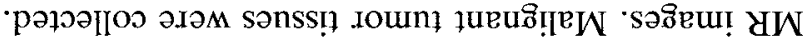

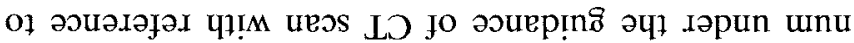

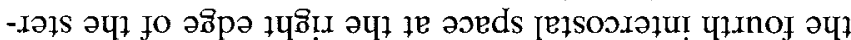

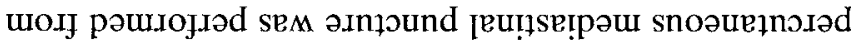
“686I" $\downarrow$ KIEnIqә

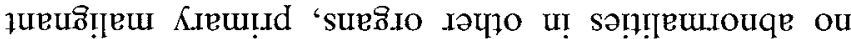

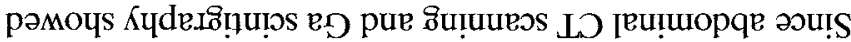

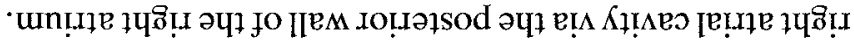

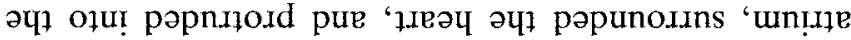

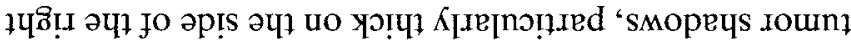
'Кџ!

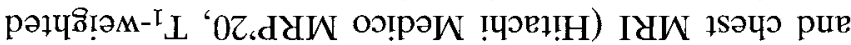

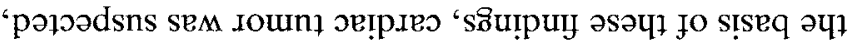

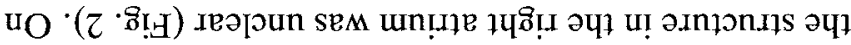

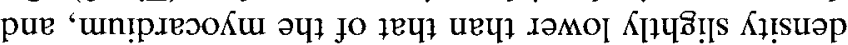

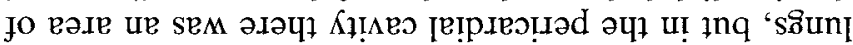

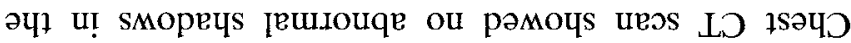

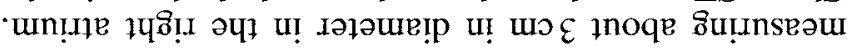

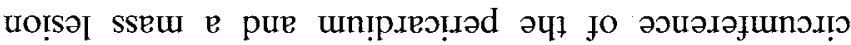

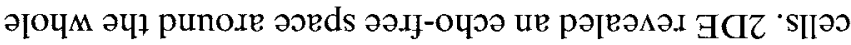

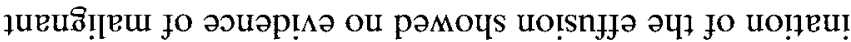

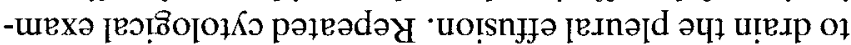

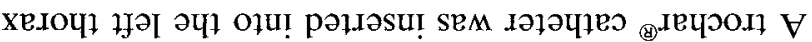

UMOYS aIV

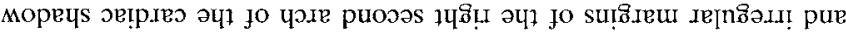

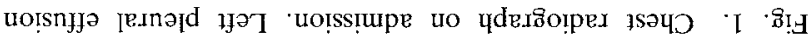

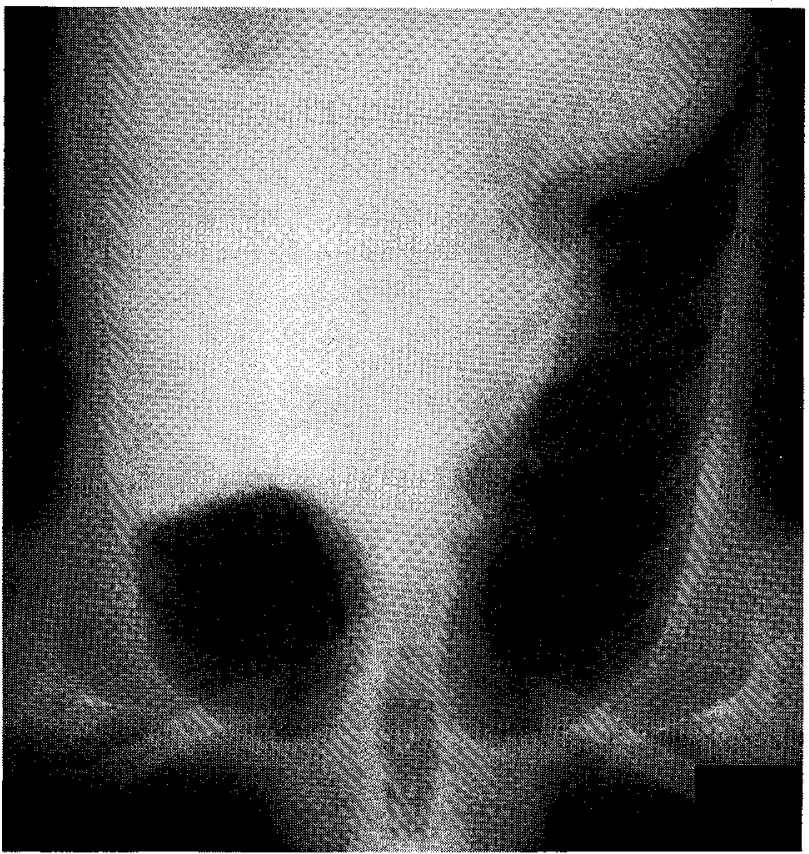




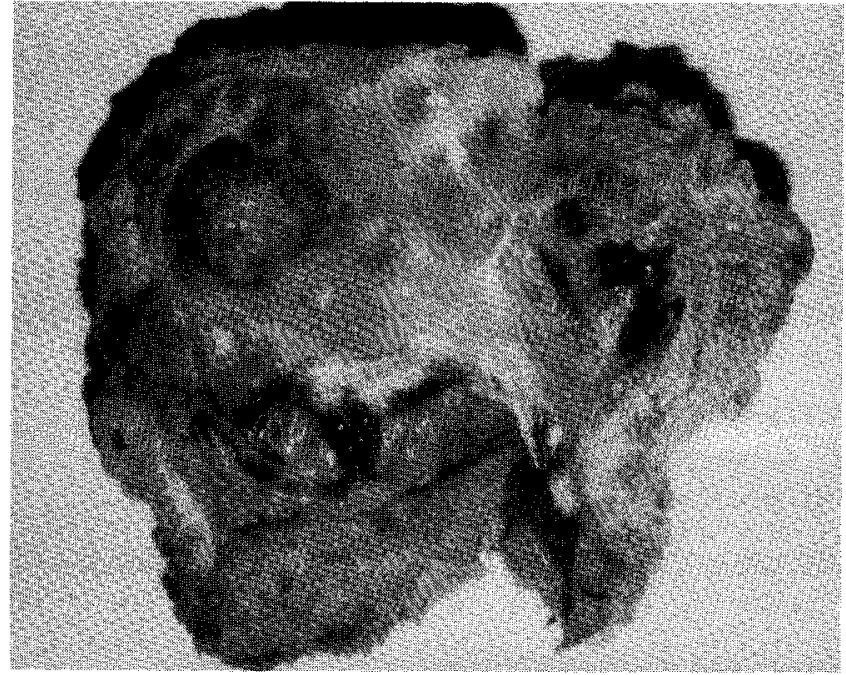

Fig. 4. Autopsy specimen of the heart with the right atrium and ventricle exposed. A tumor of the right atrial wall with an external nodule on the epicardial surface is seen.

red with Masson stain but did not stain with PTAH stain. The structures did not show positivity for Alcian blue stain or digestion with hyaluronidase, both of which are characteristic of mesothelioma. Immunohistochemical examination revealed that the tumor tissue was strongly

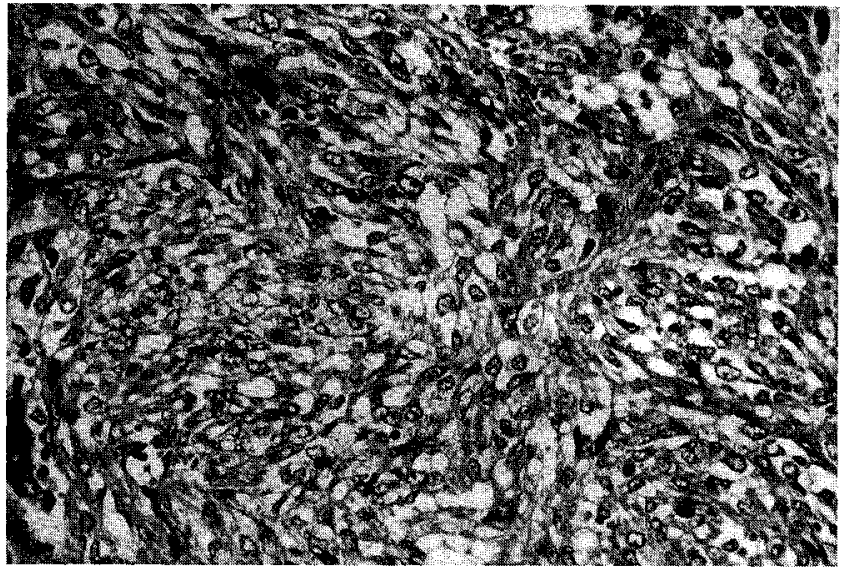

Fig. 5. Highly pleomorphic and atypical area showing some spindle-shaped cells.

positive for muscle actin or desmin which are specific for myofibrils, and also positive for vimentin, as were mesenchymal cells. However, the tumor tissue was negative for EMA, cytokeratin and factor 8, ruling out epithelial or vascular endothelial origin. These findings and the absence of any possible primary lesion in other organs led to the definitive diagnosis of primary leiomyosarcoma of the heart.

Table 1. Primary Leiomyosarcomas of the Heart

\begin{tabular}{|c|c|c|c|c|c|}
\hline $\begin{array}{l}\text { Reported } \\
\text { case }\end{array}$ & Author & Year & Localization & $\begin{array}{l}\text { Pericardial } \\
\text { invasion }\end{array}$ & $\begin{array}{l}\text { Diagnostic } \\
\text { procedure }\end{array}$ \\
\hline 1 & Weir (1) & 1940 & RA & $\oplus$ & auto \\
\hline 2 & Friedman (2) & 1944 & LV & $\oplus$ & auto \\
\hline 3 & Whorton (18) & 1948 & $\mathrm{RA} \cdot \mathrm{LA}$ & & auto \\
\hline 4 & Kennedy (3) & 1967 & RV & $\oplus$ & $\mathrm{Xp} \rightarrow \mathrm{op}$ \\
\hline 5 & Shimada (4) & 1967 & $\mathrm{RA} \cdot \mathrm{RV}$ & $\oplus$ & auto \\
\hline 6 & Sande (19) & 1970 & LA & & auto \\
\hline 7 & Hardin $(20)$ & 1974 & LA & & auto \\
\hline 8 & Bearman (21) & 1974 & RV & & auto \\
\hline 9 & Burnett (22) & 1975 & RV & & auto \\
\hline 10 & Birman (9) & 1976 & LA & & angio $\longrightarrow$ op \\
\hline 11 & Sasaki (23) & 1976 & LA & & auto \\
\hline 12 & Karasawa (24) & 1981 & LA & & auto \\
\hline 13 & Donovan $(10)$ & 1982 & LA & & auto \\
\hline 14 & Donovan & 1982 & LA & & angio $\rightarrow$ op \\
\hline 15 & Reece (11) & 1984 & LA & & op \\
\hline 16 & Fine $(7)$ & 1985 & RA & & angio $\rightarrow$ op \\
\hline 17 & Segesser (12) & 1986 & RA & & $\mathrm{UCG} \rightarrow \mathrm{CT} \rightarrow \mathrm{op}$ \\
\hline 18 & Klima (13) & 1986 & LA & & op \\
\hline 19 & Chaloupka (14) & 1986 & $\mathrm{RA} \cdot \mathrm{LA}$ & & $\mathrm{UCG} \rightarrow \mathrm{CT} \rightarrow \mathrm{op}$ \\
\hline 20 & Okabayashi (8) & 1986 & RV & & $\mathrm{UCG} \rightarrow \mathrm{CT} \rightarrow$ angio $\rightarrow$ op \\
\hline 21 & Talley (15) & 1986 & RV & & angio $\rightarrow$ op \\
\hline 22 & $\operatorname{Miki}(5)$ & 1987 & LA & $\oplus$ & $\mathrm{UCG} \rightarrow \mathrm{CT} \rightarrow$ angio $\rightarrow$ necro \\
\hline 23 & Faught (6) & 1988 & $\mathrm{RA}$ & $\oplus$ & angio $\longrightarrow$ op \\
\hline 24 & Watanabe (16) & 1989 & RA & & $\mathrm{CT} \rightarrow \mathrm{MRI} \rightarrow$ auto \\
\hline 25 & Lund (17) & 1989 & \multicolumn{2}{|c|}{ (details unknown) } & \\
\hline 26 & Takamizawa & 1990 & RA & $\Theta$ & $\mathrm{UCG} \rightarrow \mathrm{MRI} \rightarrow$ bio \\
\hline
\end{tabular}

$\mathrm{RA}$ : right atrium, auto: autopsy, $\mathrm{UCG}$ : $2 \mathrm{D}$ echography, $\mathrm{RV}$ : right ventricle, $\mathrm{Xp}$ : chest $\mathrm{X}$-ray, CT: CT scanning, LA: left atrium, op: operation, necro: necropsy, LV: left ventricle, angio: angiography, bio: biopsy 


\section{Discussion}

Cardiac tumor is a rare disease, and is usually a result of metastasis from other organs. Of all primary cardiac tumors, $75 \%$ are benign lesions, consisting mainly of myxoma and rhabdomyoma in the order of frequency. Malignant tumors are very rare, most of them being sarcoma mainly comprising angiosarcoma, rhabdomyosarcoma, and fibrosarcoma. To our knowledge, only a total of 25 cases of primary cardiac leiomyosarcoma have been reported in the literature, including 5 Japanese cases (1-24) (Table 1). Six cases with epicardial involvement have been reported to date but it should be emphasized that these only showed partial invasion $(1-6)$, where as the tumor in the present case grew in the cardiac cavity showing invasion into the whole circumference of the epicardium. The pattern of tumor growth was so unlike those previously reported that it was clinically suspected to be of pericardial origin.

In general, the prognosis of primary cardiac leiomyosarcoma is poor. Although some cases of prolonged survival after surgery and radiation therapy have been reported $(7,8)$, most cases were not operable or resulted in death soon after surgery. Surgical treatment is impossible in cases with involvement of the whole circumference of the heart, as in the present case. Here, because the progression of the disease was very rapid, neither irradiation or chemotherapy could be initiated in the present case. This suggests that early recognition of the tumor is necessary in order for sufficient treatment.

Premortem diagnosis was made in as few as 11 of the 25 cases previously reported in the literature; in all 11 cases, it was achieved through surgically resected tissue specimens $(3,6-15)$. In contrast, in the present case, MRI provided distinct tumor shadows which were not detectable by standard $2 \mathrm{DE}$ or CT scanning, and the definitive diagnosis was obtained by percutaneous mediastinal biopsy. Chaloupka et al noted the usefulness of CT scanning in their description 2 cases of cardiac tumor, but their investigation was limited to a comparison with echo-cardiography (14). The efficiency of MRI in the diagnosis of cardiac tumor has been reported by Watanabe et al (16) and Lund et al (17). They stated that this procedure is superior to any other currently available diagnostic methods in terms of the precision of the image, and unnecessity of the use of contrast media. In fact, MRI was much more useful than CT scanning in differentiating the lesion in the present case. Although the histological diagnosis was only made by biopsy, MRI provided an important clue to the clinical diagnosis of cardiac tumor, with images the same as those of intramyocardial or epicardial tumor, excluding thrombus or myxoma. We emphasize the usefulness of MRI especially at an early stage of the disease for the determination of the appropriate therapeutic regimen.
Acknowledgements: Wc wish to express our thanks to Dr. Izuru Inomata of the Department of Pathology, Jikei University, Kashiwa Hospital, and to Dr. Tadakazu Shimoda of the Second Department of Pathology, Jikei University School of Medicine, for carrying out the pathological investigation.

\section{References}

1) Weir DR, Jones BC Jr, Ohio C. Primary sarcoma of the heart. Am Hcart J 22: 556, 1941

2) Friedman B, Simard EE, Schwartz I. Unusual primary leiomyosarcoma of the heart. Am Heart J 30: 299, 1945.

3) Kennedy FB. Primary leiomyosarcoma of the heart. Cancer 20: 2008, 1967

4) Shimada N. A case of leiomyosarcoma of the heart. Saishin Igaku 22: 2581, 1967 (in Japanese).

5) Miki H, Satake H, Tominaga M, Matoba $Y$, Takahashi M. A case of left atrial leiomyosarcoma. Kokyu to Junkan 35: 203, 1987 (in Japanese).

6) Faught PH, Waller BF, Hull MT. Spindle cell sarcoma of the heart in childhood. Pediatr Pathol 8: 649, 1988.

7) Fine G, Raju BU. Lciomyosarcoma of the heart: A twenty-year cure. Henry Ford Hosp Med J 33: 41, 1985.

8) Okabayashi H, Fujiwara Y, Kanzaki Y, Mitsudou K, Yamamoto H. A case report of primary leiomyosarcoma of the heart. Ipn $J$ Thorac Surg 35: 2161, 1987 (in Japanese).

9) Birmann L, Eisenmann B, Rey G, Braganti G, Kieny R, Sacrez A. Lćiomyosarcome du cocur gauche. Arch Mal Coeur 69: $439,1976$.

10) Donovan VM, Summer W, Hutchins GM. Left atrial leiomyosarcoma. Arch Intern Mcd 142: 1923, 1982.

11) Reece IJ, Cooley DA, Frazier OH, Hallman GL, Powers PL Montero CG. Cardiac tumors. J Thorac Cardiovase Surg 88: 439, 1984.

12) Segesser LV, Cox J, Gross J, et al. Surgery in primary leiomyosarcoma of the heart. Thorac Cardiovasc Surg 34: 391, 1986.

13) Klima T, Milam JD, Bossart MI, Cooley DA. Rare primary sarcomas of the heart. Arch Pathol Lab Med 110: 1155, 1986.

14) Chaloupka JC, Fishman EK, Siegelman SS. Use of CT in the evaluation of primary cardiac tumors. Cardiovasc Intervent Radiol 9: 132, 1986.

15) Talley JD, Franch RH, Clements SD, Murphy DA, Sewell CW. Primary right ventricular lciomyosarcoma producing outflow tract obstruction. Am Hcart J 112: 1335, 1986.

16) Watanabe AT, Teitelbaum GP, Henderson RW, Bradley WG Jr. Magnetic resonance imaging of cardiac sarcomas. J Thorac Imag 4: 90,1989

17) Lund JT, Ehman RL, Julsrud PR, Sinak LJ, Tajik AJ. Cardiac masses: Assessment by MR imaging. Am J Roentgenol 152: $469,1989$.

18) Whorton $\mathrm{CM}$. Primary malignant tumors of the heart. Cancer 2: $245,1949$.

19) Sande MA, Alonso DR, Smith JP, Hook EW. Left atrial tumor presenting with hemoptysis and pulmonary infiltrates. Am Rev Respir Dis 102: 258, 1970.

20) Hardin NJ, Wilson JM III, Gray GF, Gay WA Jr. Experience with primary tumors of the heart. Hopkins Med J 134: 141, 1974.

21) Bearman RM. Primary leiomyosarcoma of the heart. Arch Pathol 98: 62, 1974.

22) Burnett RA. Primary cardiac leiomyosarcoma with pulmonary metastases. Scott Med J 20: 125, 1975.

23) Sasaki N, Hirata Y, Takao T. A case of collet-sicard syndrome by metastasis of primary cardiac leiomyosarcoma. J Jpn Soc Intern Med 65: 626, 1976 (abstract in Japanese).

24) Karasawa $T$, Shikata $T$, Yamazaki $Y$, et al. Leiomyosarcoma of the heart colliding with atrial myxoma. Acta Pathol Jpn 31: $495,1981$. 